\title{
EL ARCHIVO CAPITULAR DE SALAMANCA. DATOS PARA SU HISTORIA
}

\author{
Dr. A. Riesco Terrero \\ Catedrático de Paleografía y Diplomático \\ Facultad de Filosofía y Letras. Universidad de Málaga
}

\section{INTRODUCCIÓN}

No creo que sea el momento actual el más adecuado para hablar en favor o en contra de las instituciones de la Iglesia y, en concreto, de los Cabildos catedrales, en otros tiempos florecientes y representativos, no sólo en el ámbito eclesiástico, sino también en el campo social, económico y cultural, y hoy - por lo que a España se refiere - venidos a menos $y$, en muchos casos, reducidos al recuerdo de un pasado glorioso.

Con todo, si somos objetivos y nos limitamos, sin prejuicios, al análisis histórico de la vida, funciones y representatividad de estos organismos consultivos y moderadores de las distintas actividades religiosas, culturales, administrativas, sociales, etc., ejercidas por las iglesias diocesanas y sus legítimos representantes, los obispos, durante los siglos XII-XVIII en el área jurisdiccional de sus sedes urbanas y en el entorno territorial de los pueblos que componían sus diócesis, el balance, en términos generales, resulta positivo.

El cuerpo capitular salmantino, ubicado junto a la sede episcopal, las catedrales y el Estudio General, es, sin duda, una de las instituciones de mayor prestigio y significado dentro y fuera de los viejos muros de la ciudad del Tormes.

De esta institución formaron parte, como cabezas visibles, doctos y 
virtuosos obispos, un grupo de canónigos o cuerpo central de la corporación capitular, integrada por relevantes miembros del clero diocesano y extradiocesano, elegidos para el cargo por razón de ciencia, virtud o méritos, con un número variable y escalonado en distintos estamentos y categorías: dignidades o cargos de mayor relieve y responsabilidad, en número de ocho a diez (Deán, 4 ó 5 Arcedianos, Chantre, Arcipreste, Tesorero, Maestrescuela y Prior), ocupados, con frecuencia, por especialistas, doctores, maestros y catedráticos de la Universidad; cuerpo de canónigos de oficio (Doctoral, Magistral, Maestro de ceremonias, Archivero, Organista...) y de canónigos simples o beneficiados y prebendados mayores hasta veintiséis; cuerpo beneficial inferior, es decir, servidores de coro, racioneros, adscritos a fundaciones y capellanías urbanas y rurales relacionadas con la catedral, en número hasta de 54, y, finalmente, el personal subalterno: porteros, mozos, pertigueros, vigilantes, etc.

Esta especie de senado asesor o sanedrín del obispo actúa, como dije anteriormente, en representación del clero, a modo de coordinador de las actividades pastorales y administrativas, e igualmente, de los movimientos socioculturales promovidos en el área jurisdiccional del pastor supremo de la iglesia diocesana, convirtiéndose muy pronto en el organismo central de la administración temporal de los bienes eclesiásticos, de la planificación y vigilancia del clero parroquial y beneficial y, sobre todo, del control intelectual y moral en lo referente a enseñanza, vida y costumbres de maestros y estudiantes, principalmente de los futuros sacerdotes y aspirantes a cargos, beneficios, etc., vinculados a la jurisdicción eclesiástica.

Testimonio parlante de la recia personalidad del Cabildo catedral salmantino y de su influjo en la ciudad y provincia, compartido con el de otras instituciones de raigambre y tradición secular desde el momento de la reconstrucción y repoblación de Salamanca (s. XII), es la propia ciudad con su trazado, plazas y calles y, sobre todo, el primitivo recinto amurallado de la barriada y colación de los "Francos", perteneciente en su mayoría al obispo y estamento canonical, con edificios tan representativos como la sede o palacio episcopal, las casas solariegas de los canónigos, las dos catedrales y la Universidad, de la que dependía una amplia gama de colegios, residencias y hospitales.

De todo ello da fe la tradición, que partiendo del Fuero de la ciudad de sus ordenanzas, acuerdos y privilegios, permitió a historiadores tan preclaros como M. Villar y Macías, J. H. Cuadrado, G. Gómez Dávila, M. Gómez Moreno, F. Chueca, E. Tormo, J. González, V. Beltrán de Here- 
dia, F. Marcos Rodríguez... el milagro de hacer volver a la vida hechos y cosas muertos por el olvido, el abandono o el desamor.

$Y$ por lo que se refiere a su jurisdicción e influencia fuera de la ciudad, baste recordar que durante el reinado de Alfonso IX (aa. 11881229) la iglesia matriz de Salamanca comienza su señorio civil y su representante, el Cabildo, llega a ser una de las instituciones económicamente más fuertes de la ciudad y provincia al obtener en exclusiva el "abadengo" de parte de la Armuña, integrado por los pueblos de Palencia de Negrilla, Arcediano, Mata de Armuña, La Vellés, Carbajosa de Armuña..., sin contar su rico patrimonio de fincas, poblados y caseríos aislados (más tarde expropiados por la Desamortización), en los que ejercía su señorío como dueño y señor.

En pleno siglo XIII, tras la pérdida de la observancia canónica y vida en común de obispo y capitulares y la șeparación de bienes y derechos, surge la duplicidad de poder o dos mesas: "mensa episcopi» y la «mensa capituli».

El cardenal Gil Torres, por encargo de Inocencio IV (Constitución dada en Lyon el 7-V-1245), reconoce al Cabildo de Salamanca la jurisdicción eclesiástica plena, a modo de "prelatura episcopal independiente", y, en consecuencia, la consideración de señor con «iglesia propia» sobre la zona territorial del valle del río Huebra, enclavada en la región SO de la provincia, con un amplio radio de acción extensible a 38 pueblos con sus parroquias y poblados anejos, encuadrados casi todos en los actuales partidos de Sequeros y Ciudad Rodrigo.

Este enclave territorial, durante algún tiempo exento de la jurisdicción episcopal y más tarde en régimen de gobierno y jurisdicción alternativa, repartida por años entre el Cabildo y el obispo de Salamanca, llegó a denominarse "diócesis de la Valdobla", si bien pronto prevaleció el de "Arciprestazgo de la Valdobla", cuyo título alude a la expresión latina "Vallis de Opera", que en romance se transformaría en "Valduebra", es decir, Valle del Huebra.

Pero no es mi propósito historiar los orígenes, vida y actividad del Cabildo salmantino, ni siquiera en los momentos de mayor esplendor $y$ contundencia, cuando por voluntad real y pontificia asume la representación del clero, coordinando, en unos casos, las actividades religiosas y sociales de la diócesis, regulando o limitando, en otros, las facultades y derechos del obispo y del clero o, finalmente, vitalizando, protegiendo y dando cobijo en sus claustros -donde se albergaba la vieja Escuela catedralicia- primero al incipiente Estudio General y, después, a la célebre y pujante Universidad de Salamanca, émula de las surgidas 
poco antes en Bolonia, París y Oxford. El objetivo primordial de este trabajo, en consonancia con el título que lo encabeza, es bien distinto. En primer lugar, dar a conocer el Archivo catedralicio y la riqueza documental conservada en él, caja de resonancia y reflejo fiel de la institución que le dio vida: el Cabildo catedral. Sin perder el hilo de la temática precedente y como complemento de la misma, en segundo lugar, cumplir con un deber de gratitud para quien fue mi profesor, maestro y compañero en las arduas tareas de reorganización y centralización de los archivos eclesiásticos de Salamanca, D. Florencio Marcos Rodríguez, quien con abnegada entrega ha consagrado gran parte de su vida a las tareas docentes e investigadoras, tanto en el Seminario Diocesano y Universidad Pontificia como en la Biblioteca de la Universidad civil y, desde 1948 hasta hoy, como canónigo archivero del Cabildo catedral, al que he dedicado estas líneas introductorias.

\section{DATOS PARA LA HISTORIA DEL ARCHIVO}

Desde el periodo visigodo, las sedes episcopales, los cabildos eclesiásticos y los monasterios conservaron con verdadera estima los códices y manuscritos de carácter teológico, jurídico, literario y científico, considerando este acervo cultural como rica herencia de la tradición cristiana y faro luminoso para la extensión de la cultura y conocimiento de la verdad.

Poco después - como efecto de una triple necesidad: transmitir y prolongar su memoria, conservar los instrumentos jurídicos relativos al gobierno y administración de sus bienes y garantizar ante el Estado y los particulares la autenticidad de sus títulos mediante pruebas legales-, las citadas instituciones se ven forzadas a la creación de sus archivos, memorias vivas y actuantes de los entes que les dieron vida, órganos de gestión administrativa y depósitos de su documentación histórica.

En conformidad con la tradición eclesiástica y a tenor de los estatutos particulares y normas establecidas en sínodos y concilios, el Cabildo catedral de Salamanca, al igual que sus obispos, procuró habilitar locales adecuados para la conservación y custodia de sus libros y documentos, guardando los más ricos y los de excepcional interés junto con algunos ornamentos y objetos de culto de singular valor en arcas especiales, en alacenas empotradas en los muros y cajas fuertes estratégicamente colocadas en las propias iglesias y palacios residenciales, casi siempre provistas de rejas y complicados candados de seguridad, 
mientras el grueso de los libros y documentos corrientes se instala en alguna dependencia secundaria de la catedral o próxima a la sede episcopal.

Restaurada la ciudad por el conde don Raimundo de Borgoña y su esposa doña Urraca a instancias de Alfonso VI, e instalados en ella el obispo y su consejo, con la vuelta a la normalidad se imponen como tarea primordial la edificación de su primera catedral, la iglesia de Santa María de la Sede, y el saneamiento de los terrenos circundantes del circuito catedralicio.

La buena administración de sus rentas y propiedades, adquiridas por donación, herencia, compraventa o privilegio y su desahogada situación económica, permiten a obispo y Cabildo dedicar parte de sus bienes a la gran empresa de recuperación y reconquista del suelo patrio en manos de los árabes, tarea patrocinada por los reyes y alentada por el pontificado.

Pero el Cabildo dio preferencia a otros dos objetivos no menos loables: la creación y sostenimiento de la Universidad y la construcción - a partir de 1512 - del nuevo templo episcopal, la suntuosa catedral nueva.

La escasez, tanto de datos relativos al local destinado a archivo como de documentos conservados hasta el s. XII, no permite establecer juicios de valor, pero no cabe duda que un buen gobierno y la regulación de su propia vida y no menos las relaciones jurídico-administrativas con otras entidades y corporaciones, exigirian la conservación de sus libros-registros, actas, acuerdos y escrituras de todo tipo.

Sólo a partir del siglo XII (a. 1101) puede hablarse de archivo capitular en el sentido de serie organizada y, en cierto modo, ininterrumpida de documentos de distinto carácter y valor, formada por diplomas reales, pontificios, episcopales y, sobre todo, escrituras de compraventa, testamentos, pleitos, avenencias... relacionados directamente con el $\mathrm{Ca}$ bildo, con sus miembros o con terceras personas que actúan como intervinientes y bienhechores.

El corto número de escrituras conservadas del s. XII (110 documentos) no minoriza su importancia y valor desde el punto de vista histórico, lingüístico, jurídico, social o económico-administrativo.

La confección del primer inventario conservado, en el que se registran los fondos del viejo archivo catedral, corresponde al s. XVI.

De dicho inventario -en el que se incluye en forma global la documentación episcopal y capitular- parece deducirse que ésta se conservaja no en local especial, dedicado a archivo, sino en arcones o 
cofres fuertes, colocados para mayor seguridad en distintas estancias de la fábrica catedralicia, v. gr., sacristía, capilia mayor, capillas laterales, sala capitular, capillas del claustro y dentro de la propia iglesia.

La redacción de este índice-inventario no se acomoda demasiado a la técnica y exigencias de la normativa archivística moderna, pero no por eso carece de valor y su interés se acrecienta al proporcionarnos los datos indispensables para descubrir el orden y clasificación sistemática utilizados, al menos con los documentos conservados por obispos y Cabildo hasta el s. XVI, que serían indudablemente los más valiosos y útiles a juicio del cuerpo capitular.

En el citado inventario se habla de un cofre negro con dos cerraduras, destinado a guardar dos fardeles grandes y uno pequeño en los que se contenian, en primer término, los privilegios reales y bulas pontificias y, junto a éstos, las escrituras y títulos relativos a Buenamadre, Valdevilloria, Peña del Rey y los asientos y rentas procedentes del "peso y cuchares".

En otras dos arcas o cofres, sin descripción pormenorizada en cuanto a seguridad y colocación, se hallaban tres talegos con las escrituras relativas a la sede episcopal, Cabildo y ciudad y, formando grupos especiales, los títulos y documentación jurídico-administrativa de los capellanes de coro, arciprestazgos de Ledesma, cuarto de Baños, Medina, Alba y La Valdobla.

En las diligencias notariales de un pleito, sostenido entre canónigos, capellanes de coro y capellanes de Santa Bárbara el año 1525, se precisa con bastante detalle el lugar que ocupaba cada uno de los tres arcones o cofres, a saber, la capilla del Salvador convertida provisionalmente en sala capitular, que corresponde a la actual capilla de Talavera en el claustro de la Catedral vieja, la sacristía, donde parece se guardaba el fondo mayor desde el punto de vista numérico y, finalmente, la propia iglesia (catedral nueva), bien en la capilla mayor, bien en la parte central o junto al presbiterio. Este tercer arcón, como el anterior, era grande, de tres cerraduras y de mucha seguridad; contenia abundantes libros y escrituras.

No sabemos si esta fragmentación o división tripartita obedecía a motivos de seguridad, a una mejor sistematización de los fondos en razón de su valor, estima o utilización, a criterios peculiares en cuanto a sistema de clasificación, o, tal vez, a la circunstancia concreta de no existir un recipiente suficientemente amplio y adecuado, ni disponer de local o depósito construido ex profeso para archivo.

La obligación de consenar los "Libros sacramentales" (bautismos, 
matrimonios, confirmaciones y defunciones) y otras escrituras y libros administrativos, fundacionales, de cofradías y de censos o padrones parroquiales, etc., afectó, a raiz del Concilio de Trento, principalmente a las parroquias y a la curia episcopal, pero esta normativa y práctica generalizada fue extendiéndose a todas las instituciones eclesiásticas, de suerte que a finales del s. XVI y durante el siguiente, muchas de éstas optan por la unificación de todo el fondo documental en local apto o depósito de archivo en sentido moderno.

De la construcción o adaptación de un local para reunir los tres depósitos o arcones en que estuvo fragmentada la documentación del obispo y cabildo catedral de Salamanca no tenemos noticias hasta el s. XVIII.

Sabemos, por un acta notarial de 1737, que por entonces la documentación del Cabildo se hallaba reunida en un solo local y, en consecuencia, que la catedral contaba ya con archivo propiamente dicho, destinando para este fin una dependencia que servía de sala capitular o sala de juntas, ubicada en la parte alta del claustro donde se ha edificado más tarde parte del Museo diocesano. El local elegido, pronto resultó insuficiente y, tal vez, incómodo para albergar las crecientes remesas de escrituras y libros - fruto de la burocracia administrativa y de la ingente actividad judicial y económica de los prebendados-, procedentes, en unos casos, de la propia institución, y en otros, de personas, entidades y corporaciones ajenas al Cabildo, pero por razones de distinto orden relacionadas con él.

Resulta esclarecedor, a este propósito, el aumento espectacular experimentado en la documentación conservada de los siglos XIII al XVI, tanto en lo que se refiere a diplomas y escrituras sueltas como a libros registros.

Sólo en el siglo XIII —por fijarnos en uno de los periodos de mayor esplendor del Cabildo- Ia documentación catedralicia pasa de 110 documentos (s. XII) a cerca de 460 , iniciándose en él lo que sería la segunda sección del archivo, es decir, la serie de libros registros formada por actas capitulares, libros de cuentas, memorias de aniversarios y fiestas, padrones de rentas, relación de fundaciones y capellanías, apeos y deslindes, etc., que en siglos sucesivos (s. XIV y ss.) se completarán de forma sistemática e ininterrumpida con las cuentas de fábrica, estatutos antiguos y modernos, pleitos, escrituras de compraventa, despachos de comisarios de cruzada, calendarios con las listas de canónigos y racioneros asistentes o ausentes, etc.

El Libro 58 de Actas capitulares, fol. 561, correspondiente al acta de 
1 de octubre de 1763, da cuenta de la decisión tomada por el Cabildo en orden a la instalación definitiva del archivo en sitio más cómodo, adecuado y amplio, por parecer a los capitulares necesidad urgente poner en orden el depósito documental, evitar su amontonamiento y confuso almacenaje, salvarlo del polvo, humedad..., y posibilitar su utilización y consulta.

Durante el fructífero pontificado del obispo don Felipe Beltrán (a. 1763-1783), el maestro arquitecto don Juan Sagarvínaga llevó a cabo, de acuerdo con el canónigo doctoral y encargados del archivo, la obra de construcción del nuevo archivo en los locales inmediatos a la sala capitular y dependencias de la contaduría, ocupando la parte alta de una de las naves del claustro, cuya puerta de entrada arranca del pasillo que da acceso a la sacristía de la catedral vieja, a la altura del crucero que comunica con la puerta del claustro.

En carta-informe del señor Sagarvínaga al prelado $(6-X-1781)$ refiriéndose a la necesidad de construir y adecuar un local para archivo catedralicio, aduce estas razones: el desorden y dispersión reinante dentro de las series documentales, el peligro de desaparición de los papeles, expuestos al robo, incendio, humedad, etc., la estrechez de las salas elegidas y, sobre todo, la abundancia de materia combustible con que están construidas dichas dependencias.

Con estas obras de adaptación el archivo quedó instalado en cuatro amplias salas, la más pequeña destinada a biblioteca y las otras tres a depósitos documentales.

El depósito pequeño —que es el primero y da paso al resto de las salas - se denomina "Sala de música" por conservarse allí la mayor parte de los documentos musicales.

En la sala del fondo, que es la de mejor traza y la mayor, se guarda la documentación principal y, sin duda, la más rica e interesante, a base de sencilla cajonería de pino, rematada en graciosa crestería y dispuesta en cuatro filas cubriendo por completo - conforme a las viejas técnicas de instalación de archivos - las paredes de la sala.

Consta de 91 cajones grandes, divididos en legajos o cajas de cartón, que, a su vez, se subdividen en números conforme a una clasificación sistemática bastante rudimentaria y que la técnica actual considera defectuosa por prevalecer en ella los intereses particulares de la institución y los criterios subjetivos y utilitarios del concepto de archivo y de archivero de etapas precedentes sobre la estructuración racional y técnicas modernas en orden a la funcionalidad y valor religioso, histó- 
rico, cultural, económico, administrativo, etc., respecto de la sociedad actual y de los individuos que intenten consultarlo.

La cuarta sala es de dimensiones parecidas a la precedente, pero de construcción y mobiliario más pobre. Con estanterías de madera adosadas a los muros, conserva la documentación más moderna y de menor relieve. En su mayoría es documentación administrativa y aparece enlegajada.

Recientemente (aa. 1960-66), con la mutua colaboración del Obispado, Cabildo y Dirección General de Archivos y Bibliotecas, bajo la dirección de los maestros de obras don Jerónimo y don Ramón Andrés Herrera, don Teodoro García y el arquitecto don Amando Diego, se llevaron a cabo profundas obras de transformación, adaptación y modernización de los locales destinados a archivo catedral, cuyo titular, el Excmo. Cabildo, dando pruebas de generosa magnanimidad, posibilitó la acogida de otros archivos eclesiásticos (hasta entonces dispersos y algunos en peligro de desaparecer) en locales independientes, pero dentro del mismo recinto y formando una unidad, v. gr., el Diocesano, Clerecía de San Marcos, Archivo de la Cofradia de la Vera Cruz, Archivo de los Condes de Ardales y fondos antiguos de varias parroquias de Salamanca.

Desmontadas las cubiertas y consolidados los pisos, a base de vigas de hierro, hormigón y ladrillo, de la antigua biblioteca y archivo capitulares, algunos años más tarde se habilitaron, con el mismo sistema, otra nave del claustro más la vieja sala capitular y el local destinado a contaduría.

De esta forma, una vez consolidada la estru ctura material del edificio y suplidas, en gran parte, las estanterías de madera por otras metálicas, con un aprovechamiento del local, si no al máximo al menos diez veces mayor, la documentación de este conjunto de archivos y, en especial, la del catedralicio, se halla sistematizada por secciones mediante cajas, carpetas, legajos o libros registros y catalogada en su totalidad hasta el siglo XVII, y el resto, en avanzado estado de reorganización y catalogación.

El 28 de octubre de 1968, tras la centralización de buena parte de los archivos eclesiásticos de la capital de la diócesis, Salamanca, concluidas las tareas de restauración y transformación y en plena campaña de reorganización y catalogación de los distintos fondos, se inauguraban solemnemente los Archivos catedral y diocesano, instalados en las dependencias, antes descritas, de la catedral vieja. 


\section{FONDOS Y SECCIONES DEL ARCHIVO CATEDRAL}

El Archivo catedral de Salamanca consta, en primer lugar, de pequeña biblioteca, relativamente moderna (la antigua, rica en manuscritos, se perdió), formada por libros impresos principalmente de los siglos XVII-XIX pertenecientes a antiguos capitulares. En esta sala-biblioteca se guardan también un buen grupo de cuadernos o calendarios en pergamino en los que se anotaban las asistencias y faltas de los prebendados y algunos cantorales litúrgicos de gran tamaño.

Un segundo depósito, denominado "Sala de música», contiene las partituras y composiciones (polifónicas y gregorianas) de distintos maestros de capilla y otras piezas musicales adquiridas por la propia catedral para las funciones religiosas. Sus fondos están perfectamente ordenados y catalogados. Recientemente, don Dámaso García Fraile ha publicado el catálogo de las distintas piezas musicales bajo el título: "Catálogo Archivo de música de la Catedral de Salamanca", Cuenca, 1981.

El archivo propiamente dicho, distribuido en dos grandes depósitos, consta de dos secciones: A) SECC. DE DOCUMENTOS, subdividida a su vez en $1 .^{\circ}$ Documentación antigua de los siglos XI-XII al XVII en pergamino y papel, situada en la sala principal, y $2 .^{\circ}$ Documentación moderna y contemporáneas en papel, principalmente económico-administrativa de Ios siglos XVII-XIX, que ocupa la sala secundaria, y B) SECC. DE LIBROS REGISTROS, con las actas capitulares, libros de fábrica, estatutos, memorias, capellanías, pleitos, etc., ubicados, casi todos, en la sala principal, excepto los grandes cantorales y calendarios que se encuentran en la sala destinada a biblioteca.

La sección primera (o núcleo documental) está integrada por miles de diplomas y escrituras de todos los tipos y va del año 1098, con un original del Cid, hasta nuestros días.

La sección de libros registros es un poco más moderna, pero muy rica en datos y llena de interés para historiadores y economistas. En ésta se hallan subseries tan importantes como la de "actas capitulares", con un total de 82 libros en los que se contienen los distintos acuerdos tomados por el cuerpo capitular en sesiones ordinarias y extraordinarias, tanto sobre asuntos de régimen interno como de gobierno y administración, sin que falten los de tipo ascético y espiritual. Comienzan a finales del s. XIII (a. 1298), si bien las correspondientes a los primeros siglos (XIII y XIV) apenas se conservan y sólo desde mediados del XV puede hablarse de serie ininterrumpida. 
Dos siglos más tarde (finales del s. XV) comienza la subserie de "libros de cuentas de fábrica", con un total de 13 libros, encuadernados en pergamino, que van de 1499 a 1841, siendo el más antiguo el llamado "Benedictus» o libro padrón de rentas con datos de los años 1293-96. De esta misma época (s. XV), o bien del siglo precedente (s. XIV) o siguiente (s. XVI), son los "estatutos" (a. 1345-1549), los "calendarios» (aa. 1480-1837), los "pleitos» (aa. 1488-1583), las «escrituras de venta» (aa. 1482 y ss.), los "despachos de cruzada» (aa. 1483-1560) y los "libros de aniversario", "capellanias", "apeos", etc. (s. XV-XVIII).

Los fondos custodiados en ambas secciones, especialmente la de libros, corresponden, en primer lugar, a la documentación emanada por el propio Cabildo $y$, en segundo, a la procedente de otras instituciones y personas relacionadas con él, v. gr., papas, reyes, cardenales, obispos, abades, monasterios, ayuntamientos, curia episcopal, colegios, tribunales, vicarios, gobernadores, etc.

A raíz de la división de la "mensa" o acervo económico y jurisdiccional común a obispo y Cabildo y la separación de uno y otro en cuanto a vivienda, bienes y derechos durante el s. XIII y siguientes, probablemente se separó del archivo general la parte correspondiente a la documentación de los obispos de la diócesis, máxime la vinculada a sus personas y la recibida en razón de cargo u oficio. Sólo la documentación secreta y reservada a los prelados por la índole de su naturaleza, contenido, etc., y la separada y custodiada en armarios de mayor seguridad y garantía, conforme a las prescripciones canónicas, debió guardarse desde muy antiguo en el llamado «archivo secreto" junto a las cámaras o estancias episcopales.

Sin poder concretar el momento exacto de la separación, la cantidad de que se componia, ni las vicisitudes por las que sin duda pasó este núcleo documental vinculado directamente a las personas y actividad de los obispos de Salamanca, lo cierto es que al menos 34 pergaminos de los siglos XII, XIII y XIV descubiertos a mediados de nuestro siglo en una de las estancias del palacio episcopal están reseñados con los mismos datos y sistemas que el resto de la documentación del fondo general. Este grupo de documentos, transcritos y catalogados en 1953 por el que fuera benemérito director de la Biblioteca Universitaria, D. Fulgencio Riesco Bravo, está integrado por diplomas reales de Alfonso VII, Fernando II, Alfonso VIII, Alfonso IX, Fernando III el Santo, Alfonso $X$ el Sabio, Sancho IV, Fernando IV, Alfonso XI, Enrique II y Juan I; letras arzobispales y episcopales, principalmente de los arzobispos de Santiago y obispos de León, Salamanca, etc., y, finalmente, cartas de algunos ayuntamientos de la provincia. Este conjunto de car- 
tas de privilegio, concordias, convenios, donaciones, etc. constituye en la actualidad la base de una de las secciones del Archivo diocesano y sus fechas extremas, cronológicamente hablando, van de 1107 a 1379 .

Reseñamos, finalmente, la existencia de otros tres fondos pertenecientes al acervo documental del Cabildo y separados del mismo en épocas y circunstancias bien distintas.

Me refiero en primer lugar al grupo de documentos (en pergamino y papel) salidos del archivo catedralicio a raíz de la "Desamortización» entre 1845 y 1870 y conservados, por fortuna, en el Archivo Histórico Nacional, Secc. Clero, carp. 1879-1892 y legs. $465-478$.

Fruto de laboriosas gestiones llevadas a cabo por don Florencio Marcos, funcionario de la Biblioteca universitaria, y gracias a la buena disposición y ayuda prestada por el director general de Archivos y $\mathrm{Bi}$ bliotecas, don Miguel Bordonau y Mas, el Archivo catedral pudo recuperar en 1946 unos 6.000 documentos, sustraídos maliciosamente y de forma paulatina a raíz de la guerra de 1936 por un falso investigador a quien encubrian desaprensivos intermediarios. $Y$, por último, un tercer grupo de documentos y libros registros, tal vez el más numeroso de los tres, que damos por desaparecidos y perdidos para siempre. Las causas que motivaron su desaparición fueron múltiples. En unos casos, el abandono y falta de preocupación del Cabildo y, sobre todo, de sus archiveros; en otros, los sucesivos traslados e inadecuada instalación del archivo, la mala voluntad de investigadores y eruditos que lo frecuentaron... y, sobre todo, la eliminación incontrolada, mediante expurgos, destrucciones y ventas, de grandes lotes de pergamino y papel, por considerarlos de escasa utilidad y de ningún valor y, finalmente, el saqueo, destrozo y quema de buena parte del patrimonio documental como consecuencia de las guerras, en particular de la Guerra de la Independencia. De los estragos causados por el ejército francés en las distintas dependencias catedralicias, sin excluir el Archivo, se conservan testimonios fehacientes en la propia catedral y en sus actas.

A pesar de estos vaivenes y circunstancias adversas para la subsistencia y conservación de la documentación catedralicia, su archivo a partir del s. XII es rico en todo tipo de diplomas, especialmente reales, pontificios, episcopales, concejiles y notariales. No falta tampoco la documentación privada y la procedente de instituciones religiosas, docentes o pío-benéficas, así como la judicial, tanto en las facetas de régimen y gobierno como en otras de tipo económico-administrativo, benéfico-docente, social, urbanístico y religioso.

Sin ningún tipo de exageración ni sentimentalismo por la patria 
chica, creo sinceramente que los fondos del Archivo catedral salmantino, junto con los conservados en archivos tan importantes como el Diocesano, Histórico Provincial, Municipal y Archivo de la Biblioteca Universitaria, constituyen el núcleo central e imprescindible para la reconstrucción de la historia objetiva de la ciudad, tierras y hombres de Salamanca.

\section{LABOR DE ORDENACION Y CATALOGACION DEL ARCHIVO CAPITULAR}

Al hablar de la historia extrínseca del archivo, en cuanto local y depósito destinado a la guarda y conservación ordenada de sus fondos para utilidad de la propia institución, a modo de órgano de gestión administrativa y caja de resonancia de sus actividades, y para provecho de la sociedad en cuanto patrimonio y riqueza histórico-cultural, hice referencia a un inventario e índices complementarios, utilizados como instrumentos descriptivos de la documentación catedralicia a partir del s. XVI. Pero apenas he aludido al archivo en cuanto centro de investigación de primer orden para todo tipo de estudios históricos.

Para que los archivos históricos cumplan las funciones que hoy se les asignan, máxime las de centros de investigación, es imprescindible que sus fondos se sometan a una adecuada sistematización y orden y, en consecuencia, haber llegado a la clasificación y catalogación, tanto de las series documentales como de cada una de las piezas que las componen.

No se puede dudar del empeño y celo del cuerpo capitular -unas veces mayor, otras menor, según las épocas, nivel cultural, etc.- por conservar su patrimonio documental, al menos en lo referente al núcleo archivístico central y de interés, por lo que éste suponía en orden a la titularidad, administración, régimen y gobierno.

El concepto de archivo y de documentación antigua y moderna y su valoración han cambiado tanto, que necesariamente tuvo que modificarse la vieja idea de la persona y funciones, tanto del archivero y personal técnico como del archivo.

A partir del s. XVIII concluye la dispersión archivística de los fondos catedralicios, representada por los tres grandes arcones distribuidos por las distintas dependencias de la catedral y, no menos, por los pequeños e improvisados depósitos que se habilitaron a partir del s. XVII con el fin de centralizar todo el material en un solo lugar, conservarlo mejor y facilitar, en lo posible, su utilización y consulta. De esta forma 
el Archivo capitular deja de ser almacén polvoriento y desorganizado para convertirse poco a poco en depósito organizado de la documentación administrativa e histórica del Cabildo.

No se puede hablar de clasificación y ordenación archivística técnica ni pormenorizada mediante guías, inventarios, catálogos e índices dentro del Archivo catedral hasta tiempos muy recientes.

La clasificación archivística, antigua y moderna, hasta mediados del siglo actual, ha sido rudimentaria, insuficiente $y$, en muchos casos, defectuosa o nula.

Sometida la documentación a la clásica sistematización que agrupa los fondos en pergaminos, papeles (legajos, expedientes, etc.) y libros manuscritos, estas clasificaciones sucesivas resultan incompletas $y$, por supuesto, rudimentarias.

Ignoramos quiénes fueron los autores de estas someras clasificaciones que en forma de breves anotaciones, coetáneas o posteriores a la génesis y factura de cada documento, fueron colocándose durante los siglos XII-XVI en el vuelto o márgenes de los pergaminos más importantes. Con el tiempo —en nuestro caso a partir del s. XVI-, tales anotaciones, de una o varias líneas a modo de regesta o resumen, escritas o rotuladas en diferentes grafías sobre el propio documento, terminan por pasarse a papeletas, cédulas, folios, cartelas, etc., independientes que, a veces, se multiplicaban de forma que una de ellas quedaba cosida al diploma y la otra — cuando existía - pasaba al cedulario, base del incipiente fichero moderno.

Estas anotaciones escritas en el propio documento o sobre papeletas independientes, más o menos vinculadas a los diplomas, aparte del resumen documental, nos proporcionan la signatura topográfica, identificadora del documento en cuanto a sección y lugar de ocupación dentro del archivo.

No es raro encontrar junto a esta especie de ficha identificativa otras notas archivisticas, históricas o administrativas y mil curiosos detalles más, añadidos o incorporados por archiveros y estudiosos a lo largo de los siglos.

Al s. XVI corresponde — como indiqué más arriba - el primer inventario catedralicio en forma de libro o cuaderno. Lleva por título: "Libro indice antiguo de los papeles e instrumentos que en aquel tiempo habia en el Archivo de esta Santa Iglesia Catedral, y consta de 88 folios útiles sin contar algunos más en blanco. Su lectura y estudio proporcionan una idea bastante exacta de la clasificación y organización del material archivístico en esta época. 
La relación de los documentos reseñados es incompleta y bastante somera. La reseña, en forma de registro breve, se limita al contenido documental incluyendo, por lo general, la data, interés o motivación y fecha topográfica. En determinados casos falta la data y, fácilmente, se observan adiciones complementarias de épocas posteriores.

Aparte del inventario precedente, se conservan algunos otros más recientes y de carácter administrativo, destinados a reseñar los documentos principales con estos títulos: "lndices de todos los censos, escrituras de compra-venta, hacienda y adjudicaciones de memorias, de capellanias y de títulos... de la Santa Iglesia Catedral de Salamanca". Otro, todavía más limitado por referirse sólo a las posesiones del Cabildo y a su ubicación y rentas, se denomina: "Indice de los instrumentos de la hacienda de los señores Deán y Cabildo de la Santa Iglesia Catedral de Salamanca».

Todos estos inventarios van desde mediados del s. XVIII (a. 1740) hasta finales del XIX (a. 1882) y están provistos de índices alfabéticos con los nombres de los lugares y alguna otra indicación que facilitan la búsqueda y localización tanto del documento como de la finca, propiedad, renta, etc. en cuestión.

Esta era la situación del Archivo catedral a mediados del s. XX. Un archivo viejo e inadecuado en cuanto a edificio y comodidad, húmedo y oscuro, sin medios materiales en cuanto a sala de investigación, ficheros, estanterias, cajas, carpetas, luz eléctrica, servicios higiénicos, calefacción, mobiliario, etc.

Y por lo que se refiere a organización interna, sin organigrama ni planificación archivística definidos, ya que los índices-registros o inventarios existentes hasta el s. XX no pasan de elencos parciales de carácter orientador, confeccionados para facilitar el recuento, ubicación y manejo de los fondos más apreciados por su utilidad e interés histórico.

Y en cuanto a las anotaciones identificativas colocadas en los márgenes de la documentación, en el propio dorso o en cédulas independientes, cosidas a los diplomas reales, eclesiásticos o privados, tampoco suponen una clasificación adecuada en cuanto a uniformidad, método y eficacia.

Las fichas sueltas (cédulas o papeletas), agrupadas a modo de fichero, aparte de escasas y sin rigor técnico, eran incompletas en cuanto a datos y de escasa utilidad para el investigador.

El concepto de archivo y de documento - como puede observarse- no respondía al actual. El archivo y su sistematización, en 
cuanto órgano de gestión administrativa e igualmente el documento o escritura, en calidad de prueba testimonial y título legal, estaban exclusivamente al servicio del propietario o institución que les dio vida sin pensar para nada en ese otro aspecto tan interesante: el archivo y documentación como bien cultural, como reflejo y memoria viva de la sociedad y como centro e instrumento de información y base de la investigación histórica.

Por otra parte, existen numerosas causas y circunstancias aclaratorias, cuando no decisivas, de la crisis y compleja problemática que arrastran desde siempre estos grandes olvidados: los archivos, pero especialmente los eclesiásticos, v. gr., el escaso interés de las autoridades, la falta de preparación técnica y vocacional del personal dedicado al archivo, la pobreza de numerosas instituciones que impide una remuneración digna y la consiguiente dedicación del personal, la ignorancia y desprecio por el patrimonio documental, etc. El mismo concepto de oficio y beneficio eclesiástico, recogido en la legislación canónica y la aplicación concreta del mismo por parte de las constituciones y estatutos de cada Cabildo a la persona y cargo del archivero dejan mucho que desear.

Con frecuencia, el cargo de archivero eclesiástico (catedralicio o diocesano) ha venido recayendo en personas relevantes en méritos pastorales o en otros campos de actuación, pero ajenas al oficio en cuanto a preparación técnica y vocación archivística.

Las figuras y funciones del archivero eclesiástico, tan diluidas y sin importancia en el extinguido Código de Derecho Canónico del 1917, subsisten en el que ahora (a. 1983) acaba de estrenarse. Pero todavía resulta más preocupante, en un futuro próximo, la vida de estos archivos dependientes de instituciones eclesiásticas, como los Cabildos, totalmente transformadas en cuanto a número, proyección y funciones. ¿Tendrán los Cabildos catedrales interés en conservar y transmitir ordenadamente a la posteridad el patrimonio que recibieron de sus antepasados?

¡Ojalá que la nueva línea pastoral y litúrgica, marcadas a los Cabildos reformados no menosprecie aspectos tan importantes para la lglesia como el cultivo de su propio patrimonio cultural y científico y dejen de ser letra muerta las palabras de Pablo VI, "el más modesto documento conservado como fruto de la actividad de la Iglesia constituye un signo de su presencia en el mundo, un argumento de su misión y una huella del Cuerpo Místico en el secular camino de la historia" (alocución Salutiamo dirigida a los participantes en el VI Congreso de la Asociación Archivística Eclesiástica, 6-XI-1964). 
Reducir las obligaciones del director del Archivo catedral a atender su archivo y al personal investigador, única y exclusivamente mientras se celebra el culto público y el resto de los capitulares permanecen en el coro, o ir a dicho centro sólo cuando se le reclama por el propio Cabildo o por los particulares, supone la inactividad interna y externa del archivo e imposibilita la catalogación y la consulta.

Afortunadamente esta inveterada y frecuente situación ha ido desapareciendo y, en la actualidad, la mayoría de los archivos eclesiásticos, capitulares y diocesanos, se han modernizado, más de 30 han publicado sus catálogos, guías, inventarios, etc., y la mayoría, a pesar de las estrecheces económicas y mala retribución, abren generosamente sus puertas al público, bien durante toda la jornada, bien algunas horas.

Don Florencio Marcos Rodríguez, salmantino de nacimiento y convicción, tras doctorarse en ciencias eclesiásticas y superar la licenciatura en Filosofía y Letras en las Universidades Pontificia y Civil de Salamanca, se incorpora por oposición al Cuerpo Facultativo de Archiveros y Bibliotecarios del Estado y con esta excelente preparación científica y técnica accede, también por oposición, al cuerpo capitular ocupando desde 1948 el cargo de Canónigo archivero de la catedral. La herencia que el doctor Marcos Rodríguez recibe, en razón del cargo, a mediados de siglo, si bien rica en contenido y valiosa en significado, puede considerarse pobre en cuanto a edificio, instalaciones, clasificación, ordenación y catálogo de fondos documentales.

Durante estos 35 años de labor callada y constante, sin atenerse a la estricta obligación reglamentaria en cuanto a horas de trabajo, don Florencio, director del Archivo catedral y del Museo diocesano, ha conseguido transformar el edificio y locales en que ambos centros se albergan. $Y$ con relación al viejo e inadecuado caserón adaptado en el s. XVIII por el arquitecto Sagarvínaga para archivo, puede decirse que gracias a su esfuerzo y desvelos Salamanca cuenta con un centro de investigación de primer orden, de gran utilidad para sus Universidades y estudiantes, lugar agradable y relativamente cómodo en cuanto a instalaciones indispensables, mobiliario, estanterías, luz (natural y eléctrica), calefacción, sala de investigadores, depósitos de conservación, horario de trabajo, etc.

Pero mucho más importante, con serlo, que la transformación y adaptación moderna del inmueble-archivo, puede considerarse la labor achivística y profesional de su director.

Respetando - por razones obvias- la defectuosa clasificación sistemática impuesta por sus predecesores en el cargo, don Florencio ha 
perfeccionado cuanto recibió y, en diversas etapas, ha logrado la catalogación íntegra e individualizada de los fondos documentales del Archivo catedral correspondientes a los siglos XI-XVII.

Este gran fichero descriptivo - se aproximan a las 25.000 fichas catalográficas - confeccionado con máximo rigor técnico y ordenado en base a criterios de orden cronológico, alfabético (onomástico), topográfico y toponímico permite al personal del archivo y a cualquier persona extraña localizar e identificar el documento concreto a través de su contenido, notas individualizantes, cuadros clasificatorios, etc., y alcanza su máxima expresión en los catálogos.

Convencido de que las funciones principales del archivero no podían reducirse a recoger y conservar la documentación, don Florencio se ha considerado obligado a servir y entregar para su consulta los fondos custodiados en el archivo, facilitando el acceso, orientando a los investigadores y, sobre todo, dándolo a conocer mediante artículos científicos y divulgativos.

Con la publicación del Catálogo de documentos del Archivo catedralicio de Salamanca. Siglos XII-XV (Salamanca, 1962), el doctor Marcos Rodríguez - aparte de dar a conocer la riqueza histórica oculta en libros y diplomas - ha puesto en manos de profesores, investigadores, estudiantes $y$ eruditos un instrumento de trabajo de excepcional valor científico, informativo-descriptivo y de localización.

Gracias a este Catálogo conocemos la historia y estructuración del Archivo catedral y, a través de sus fichas, a nadie pasará desapercibido el número de orden, la fecha actualizada, la tipología documental, su autor, contenido y destinatario, la fecha conforme al original, datos externos de cada diploma o libro (tradición, medidas, material soporte, tipos gráficos, estado de conservación, valor artístico...), signatura y, cuando procede, datos bibliográficos y estudios relativos al documento descrito.

El citado Catálogo - reflejo fiel de parte de la labor archivística plasmada en los ficheros - se inicia con breve resumen histórico del archivo, y tras la catalogación de 1172 piezas, concluye con un resumen de la Sección de libros registros: actas, cuentas de fábrica, aniversarios, capellanias, pleitos... y dos índices, uno de personas y cargos, y el otro, de lugares, ambos alfabetizados.

La elaboración y publicación del catálogo correspondiente a los siglos XVI-XVII y la preocupación por el futuro inmediato de este centro cultural son, sin duda, las metas acariciadas por este archivero ejemplar y alma del Archivo catedral. 
No quiero hacerme interminable citando los múltiples trabajos científicos y de divulgación escritos por don Florencio sobre la catedral, la Universidad y los Archivos catedralicio y universitario. Pero sería imperdonable, por lo que al Archivo catedral se refiere, omitir la reciente publicación de los textos documentales del s. XII conservados en su depósito o sala principal. De dicha publicación: Documentos de los archivos catedralicio y diocesano de Salamanca. Siglos XII-XIII, Salamanca, 1977, al director del Archivo catedral ha correspondido la preparación del núcleo más antiguo y valioso, ofreciéndonos, junto a la transcripción, el regesto y ficha catalográfica de 110 piezas de gran valor para la historia política, social, económica, religiosa y lingüística de la ciudad del Tormes y su alfoz.

El Archivo capitular y, no menos, el Cabildo y la propia Salamanca pueden felicitarse por el gran acierto y fortuna de haber tenido al frente de este gran centro documental a tan ejemplar archivero, de sólida formación técnica, humanística y eclesial.

Sirvan estas sencillas líneas -escritas por el que en otro tiempo fuera su fiel colaborador- de reconocimiento y homenaje a la amplia labor archivistica de quien, con tanto celo y cariño, puso a disposición de estudiantes, profesores e investigadores su acertado hacer y saber y que el Omnipotente le siga iluminando y conservando para que continúe y complete la labor que iniciara hace ya tantos años.

Málaga, 1983 